\title{
The Other Side of the Desk: Experiencing Learning a New Language
}

Norman Diffey

The article discusses the comments of thirty in-service ESL teachers who participated in introductory lessons to an unknown language (Russian). The comments indicate high levels of anxiety and a need for security before and during instruction. Culturally conditioned needs such as the display of competence and control may influence these feelings with adults in particular. Various cognitive techniques employed to master the material as quickly as possible were sometimes highly idiosyncratic and seemed to reflect the need to retain control. In general, the participants evidently gained a number of practical insights into different aspects of classroom second-language instruction.

ESL teachers in Canada are more likely than teachers of FSL to be unilingual. It is conceivable that some have never undergone the experience of studying another language, and it would certainly not be considered abnormal for them to be ignorant of their students' first languages. As a result, they may be less equipped to recognize and respond to difficulties encountered by their students, especially in those crucial early stages that seem to influence such determinants of success as self-confidence and persistence. Regardless of any long-term instrumental or integrative motivation on the part of the students, the immediate concern for the teacher is helping them to get started, which means primarily addressing a number of complex and involuntary affective obstacles, variously referred to as culture shock, language stress, affective filter and the like (Stern, 1983: 360-90; Brown, 1987: 99-121). Unless she has experienced such stress herself the teacher may be insufficiently aware of its reality for the learner. In more general terms the ESL teacher who was never an L2 learner may assume that the individuals quietly assembled before her and so politely submitting to her direction may have no personal thoughts or preferences regarding the types and management of the activities presented for their benefit.

The Education Faculty of the University of Windsor recently offered the Ontario Ministry of Education additional qualifications course, "ESL Part I," with an enrolment of about thirty practicing and non-practicing, present and aspirant, teachers of ESL in elementary, secondary and adult education. For reasons of geography and tradition, Windsor is one 
of the country's most important centres for the reception of new Canadians, and ESL programmes continue to expand at all levels, from primary to community college. Most participants in the course professed little or no knowledge of psycholinguistic theory and stated they had taken no previous course in L2 methods. It was decided as an initial exercise in consciousness-raising to expose them to a limited period of instruction in an unknown language and to have them record, for discussion, any personal feelings and strategies they became aware of during the experience. The idea of role-reversal is not new in L2 teacher training (Devitt \& Czak, 1981; Lowe, 1987). It was of some interest in this case that the participants' comments often appeared to "echo the literature" despite their professed ignorance of theory. Asked to identify a common thread running through these reports, one might select the theme of control, since in various ways they appear to express an urgent need on the learners' part to gain immediate control of the learning situation, to reduce as quickly as possible the uncertainties of an inherently meaningless and formless situation.

Russian was chosen, being unknown to all the participants, although it was recognized that an advantage would be enjoyed by a small number who spoke one of the other Slavic languages. Two half-hour classes for beginners were conducted on successive weeks by an instructor from the languages department. Using an aural-oral approach with some exposure to the written code towards the end, the lessons were intended to teach a limited everyday vocabulary for understanding and pronunciation. The tone of a number of the reports suggested a high degree of personal involvement in the learning process. Despite their unstructured nature it was surprisingly easy to classify the comments within two main categories, describing first the sometimes powerful affective reactions experienced and secondly the variety of individual strategies used to deal with them. Comments on personal qualities of the instructor in such areas as empathy and patience were generally positive, suggesting that any negative feelings could not usually be ascribed to that source. Scattered throughout the reports were a good number of practical insights relating to classroom strategies, particularly for dealing with novices, and these were elaborated during the follow-up discussion.

\section{Affective reactions}

A frequently reported feeling was an anticipatory anxiety or general tenseness before the first lesson and sometimes before the second also. One student attributed this to previous negative experience in learning a language. Another experienced headaches a few minutes before the start of each lesson. Whether or not the initial apprehension was dissipated 
once the lesson began apparently varied from one student to another. In a number of cases a "second wave" of anxiety was produced by the first exposure to the unfamiliar sounds. One noted a sense of helplessness, since "nothing seemed familiar or known." Panic and confusion on first hearing Russian was a typical reaction. "When Russian vocabulary bore no relationship to English or French, I realized that language learning was a much more formidable task than I had thought." A sudden realization of the magnitude of the task before them was a commonly felt experience at this early stage. Frustration, embarrassment, feelings of inadequacy, and regret over the absence of a "safety net" were noted. Several students were surprised by these feelings in view of the low-risk nature of the situation, with no final evaluation. In more than one instance such feelings were made more acute by the realization of personal limitations. Surprise and depression at the readiness to give up in the face of difficulty was reported in these cases. The first encounter with the Cyrillic characters occasioned the following remark: "The sounds of the words and the letters used to form these words were very confusing. I believe that this was the time that I began to turn off. I didn't understand these strange letters and I simply didn't want to learn Russian." A perfectionist tendency, to be expected in a group of this kind, tended to heighten such frustrations, as with the student who reported a sense of deflation at not being able to recall all the new words encountered. For some, realizing the limitations of their memory came as an unwelcome surprise. Conversely, another was aware of feelings of pride at the successful recall of a word.

A third kind of affective reaction might be described as the "saturation point." While it may not have been reached by all students at the same time, several saw fit to refer to the moment when, in the words of one, "my mind was screaming for him to stop. I recognize that after 30 to 40 new words were flooding my brain, the saturation point was reached." "Hey, I need a break-my head is full." A note of "advice" to the instructor suggested allowing a "quiet time for assimilation and internalization," an interesting nod in the direction of Silent Way and kindred methods in the Krashen and Terrell tradition. The stress caused by feelings of saturation sometimes took the form of fatigue, initially mental fatigue nurtured by the student's belief in the finite nature of his/her mental capacity. Once this point was reached, resistance to further input became quite strong. In some cases physical exhaustion seemed to follow.

Regarding the well-researched phenomenon of "language class stress," we found that from the practitioner's viewpoint it might be useful to see it in association with the different stages of the learning process. Initially, perhaps, the prospect of exchanging a familiar for an unfamiliar mental landscape causes feelings of apprehension likely to be intensified by any previous negative experience of learning a language. Such feelings may 
then be confirmed by the first encounter with the strange new sounds and forms: the first taste of "language shock" (Schumann, 1975). Even if these are allayed for a while, the teacher should perhaps still be vigilant for signs of a tendency to quit at a stage when the learner senses, correctly or otherwise, that a limit has been reached. If student anxieties could thus be categorized as, say, "anticipatory," "confirmatory" or "terminative," the teacher might be better prepared to adjust the content and pacing of activities accordingly.

If nothing else, the reports served to substantiate Krashen's assertion that "language lessons inspire fear even among professional language teachers, and one of the reasons for this is our insistence on early speaking and our attitudes towards errors. Why make students suffer from procedures that are unpleasant even to us?" (1982: 75-76). This thinking has, of course, influenced various humanist L2 methodologies such as Suggestopedia, Counseling-Learning and the Natural Approach. Nevertheless, with adults in particular, the teacher may still have to expend some initial effort in convincing the learners themselves that the rules have changed. Besides their own previous experiences, likely derived from a traditional L2 learning environment, they may have to deal with culturally imposed values which place a premium on excellence and competition in the "classical humanist" tradition (Clark, 1987: 5-13). This concern tended to surface in a number of references to the role of the group, which was seen as a source of security. Although the instructor chose to drill pronunciation in the group rather than individually, this did not prevent some from fearing that sooner or later his approach would change: "It was interesting for me to note that throughout the lesson I felt an underlying discomfort. This was a remnant from my language learning days in high-school. I was constantly hoping he wouldn't centre [single?] me out to say something." Another student noted a tendency to compare self with others even though it was recognized as "non-productive" to do so. On the other hand, while some appreciated the protective anonymity of the crowd, others wanted to "have a go" at pronouncing the words individually. A similar division of opinion showed itself in the comments regarding method. Those who favoured the group saw the aural-oral approach as having the virtue of treating everyone equally. Group repetition, for example, was seen as reassuring in the case of phonetic difficulties. The "individualists," on the other hand, claimed that they had hoped for more meaningful interaction, facilitated by the learning of "communicative" vocabulary such as the Russian expressions for "Hello" and "How are you?"

The reports and subsequent discussion thus suggested a possible need for some reeducation of learners, particularly in the case of adults, who (for the reason noted earlier) make up an important part of the local ESL 
clientele. While their mind-set and past experience may pre-dispose them to come to class intent on preserving their dignity,- what the sociologist Goffman (1959) calls "front,"-it appears that the various relational modes we typically adopt in our daily encounters,-competitive self-assertion, the appearance of competence and control,--are perhaps best left outside the language classroom door. Questions of self-image, which seem to be particularly important for adults (Knowles, 1980) may have underlain the observations regarding the teacher-learner relationship. One student decided at the outset to view the instructor's techniques from a detached, analytical perspective but admitted having learned very little. The more typical attitude might best be summarized as willing submission, faith in the instructor's ability to lead the learner into unknown territory. This return to the parent-dependent state of the infant in the early stages of learning a language has been labelled variously as "handicapped regression" (Curran, 1976: 27-28), "satellization" or "infantilization" (Stern, 1983: 382, 398-400). Some commentators appeared to recognize the necessity of mentally assuming such a role in relation to the instructor and linked their success to the degree of submission attained.

\section{Coping strategies}

The variety and originality of learning strategies and the general sense of their importance seemed to reflect a sense of urgency in the processing of large quantities of new and complex information: the need to keep this "under control for myself," as one wrote. Perhaps adults, much more than children, are susceptible to thinking globally of the task of learning an entire language, a prospect that can be truly overwhelming. Obviously in this case the students were aware of the limited duration of the experience and that the measure of success would be their degree of mastery of the limited material achieved by the end of the second class. Nevertheless, their priority from the outset was the gaining of immediate cognitive control over the incoming material. One wonders to what extent such learners would, in a full programme, be content to relax and take their time even if advised to do so.

For the novice L2 learner the main focus is the decoding of lexical items rather than structures (Omaggio, 1986: 20-22). A variety of strategies were used for understanding and memorizing words and, based on the concrete examples given, it was possible to rank them according to the frequency with which they were reported. Although the catalogue contains few surprises, it was of interest to note the creative extremes to which learners sometimes go in their application of mnemonics and so forth to specific items. The reports yielded the following list: 


\section{1) Cognates}

Examples: lampa ${ }^{I}=$ lamp; stul $(=$ stool $)=$ chair. Sometimes a third language became involved: karta $(=$ French carte $)=$ map. The resemblence could also be philologically coincidental: $d a$ (apparently $=$ yeah $)=$ yes.

\section{2) Personal mnemonics}

"Word association, whether in sound or in meaning, was my most often used strategy." Examples: vilka (may be used to eat veal) = fork (noted by two students). [To differentiate karta from kartina] "I associated carte to the French word for map and cartina sounds pretty and a picture is pretty." ". . . when the word for chalk [mel] was introduced, phonetically it was like a French word. This allowed me to associate it, as crazy as it seems, with honey-sweet chalk? . . Any kind of connection or rhyme or collection of letters usually helps me to retain the word." One student even associated the sound of the word for tie [galstuk] with the English gallstone. An interesting discussion point was the apologetic, even embarrassed, tone with which students divulged their personal mnemonics. Curran, stressing the importance of such "nonsense relationships," encourages students to share them with each other, since doing so involves the sharing of feelings, perceptions and personal memories which fear of exposure to ridicule may incline us to leave concealed (p. 77). Blair (1982) sees their use in the early stages of learning a language as an effective means of isolating salient features from the mass of incoming, initially incomprehensible material. Students should perhaps be encouraged by example to make use of private mnemonics in dealing with new material, without having them imposed by the teacher or other students.

\section{3) Visual association}

The instructor's ample use of kinesics to convey meaning was seen as helpful, although concrete demonstration sometimes led to ambiguity. An example of polysemy was supplied by the black pen intended to illustrate chyerniy (black), which was interpreted by one student as pen.

\section{4) Written production}

A number of students could not wait to be "formally introduced" to the written code and found it helpful to fix the shape of the new words by immediately jotting down English orthographical approximations. A graphic representation of a word is permanent, whereas a phonic one is ephemeral and beyond the "control" that seems important at this stage. To 
prohibit inventive writing of the new language, for doctrinaire reasons, might therefore prove counterproductive.

\section{5) Delayed oral production}

Some learners were unwilling to repeat words until they were quite sure of their meaning. A sense of discomfort was reported at making sounds unconnected to meaning. Delayed production was also seen as necessary to complete the phonetic analysis of the word, i.e. sounds were mentally shaped before being imitated: "I needed to hear the words several times before I felt secure enough to begin to say them." Premature production was seen as interfering with this important phase: ". . . in an effort to correct my pronunciation I stopped repeating the words so I could concentrate on hearing the unfamiliar sound combinations." Three students on the other hand found early, frequent repetition to be reassuring, but did not indicate whether this preceded or followed meaning.

\section{6) Heuristic strategies}

Conscious use of problem-solving logic was reported by two students who tried to infer a general rule for plural formation and by one who resorted to counting the symbols in the written forms displayed so as to compare their length with those of the words encountered aurally: "Words containing fewer symbols had to be either carte, stool, or stole, and those containing more symbols had to be gazietta, cartina, etc."

\section{Implications for instruction}

From the topics that have been developed here as major themes of the reports, along with other suggestions scattered throughout them and/or volunteered in the subsequent discussion, one might summarize the main conclusions of the group in the areas of planning and pacing, instructional techniques, content, and interpersonal relations.

\section{Planning and pacing.}

(a) Establish the salience of one item only at a time, but carefully limit the length of presentation.

(b) Allow time and opportunity to use the four skills.

(c) Avoid overwhelming the students: "I would suggest short periods of high and/or less concentration. ..."

(d) Alternate between activities involving repetition and interactional ones.

(e) Conduct frequent reviews.

(f) Allow time for "assimilation and internalization." 


\section{Techniques.}

(a) Make presentations as visual as possible, using unambiguous realia.

(b) Correct pronunciation frequently in the early stages (e.g. by syllabification), with particular attention to phonetic features peculiar to the target language.

(c) Use cognates whenever possible.

(d) Build on what is known.

(e) Present vocabulary in clusters, e.g. words for knife, fork and spoon.

(f) Allow opportunities to "do things" with what has been learned, e.g. drawing and labeling.

(g) Provide opportunities for questions about the language and help students see its patterns, but avoid protracted discussions in the L1.

\section{Content.}

(a) Teach interactional expressions (Hello, How are you?) early.

(b) Include some writing as early as possible.

(c) Select vocabulary having a high degree of usability (surrender value).

\section{Relations.}

(a) Create a relaxed and reassuring atmosphere.

(b) Allow individuals the right to refrain from group repetition until they feel ready to participate.

(c) Allow individuals to try things alone (e.g. pronouncing) if they seem willing.

(d) In each individual case, be alert for the "I give up moment."

\section{Conclusion}

Gauging learners' thoughts and feelings is one of the greatest challenges for any language teacher. Placing ourselves in their shoes occasionally is a useful technique for reminding ourselves that their participation in the learning process is sometimes painful and slower than we would wish, but by no means as passive and unconditional as we might suppose. This principle holds for learners of any age. More specifically the mature learner might be seen as embarking on a process of establishing a form of control by various inventive means, perhaps to enjoy the sense of acceptance with normal adult interactions.

An increased awareness of the sensitive nature of the learner's feelings, self-image and individual priorities was seen as a valuable outcome of this experience. Although the "insights" gained may strike the experienced teacher as a mixture of didactical principles that are in some cases obvious and in others open to discussion and qualification, the main value of the 
exercise was that the participants obtained them through experience and reflection rather than reading professional literature (which in the last resort frequently elaborates theories and constructs such as "communicative competence" that may appear irrelevant from a perspective of classroom survival). This kind of sensitization may be particularly important in the preparation of ESL teachers who, in the Canadian context at least, cannot necessarily be presumed to have the formal background of teachers of other languages.

\section{NOTE}

1. The Latin alphabet will be used in transcribing the Russian words, which are also given in their original version in the student reports.

\section{REFERENCES}

Blair, R. W. (1982). Easification. In R.W. Blair (Ed.) Innovative Approaches to Language Teaching, 218-225. Rowley, Mass.: Newbury House.

Brown, H. D. (1987). Principles of Language Learning and Teaching. Englewood Cliffs, N.J.: Prentice Hall. (Second edition).

Clark, J. L. (1987). Curriculum Renewal in School Foreign Language Learning. Oxford: Oxford University Press.

Curran, C. A. (1976). Counseling-Learning in Second Languages. Apple River, Illinois: Apple River Press.

Devitt, S. M. \& I. V. Czak. (1981). An experiment in the teaching of Russian to future language teachers. Canadian Modern Language Review, 38 (1), 43-57.

Goffman, E. (1959). The Presentation of Self in Everyday Life. Garden City, N.Y.: Double Day.

Knowles, M. S. (1980). The Modern Practice of Adult Education: From Pedagogy to Andragogy. New York: Cambridge.

Krashen, S. (1982). Principles and Practice in Second Language Acquisition. Oxford: Pergamon Press.

Lowe, T. (1987). An experiment in role reversal: teachers as language learners. ELT Journal, 41 (2), 89-96.

Omaggio, A. C. (1986). Teaching Language in Context: Proficiency-Oriented Instruction. Boston: Heinle \& Heinle.

Schumann, J. H. (1975). Affective factors and the problem of age in second language acquisition. Language Learning, 25, 209-235.

Stern, H. H. (1983). Fundamental Concepts of Language Teaching. Oxford, etc.: Oxford University Press.

\section{THE AUTHOR}

Norman Diffey (Ph.D. McGill, 1975) has taught French, German and English as 
second languages. Formerly a department head at Laurentian Regional High School in Lachute, Quebec, he is presently Assistant Professor in the Faculty of Education, University of Windsor, involved in pre-service teacher training in FSL, in-service courses for teachers of FSL and ESL, and graduate studies in second-language teaching and learning. Research interests include second-language curriculum and programme design. He has also published in the area of German literature. He is a member of the Executive of the Windsor Affiliate of TESL Ontario. 